\title{
The Efficacy of Academic Reading Strategy Instruction among Adult English as an Additional Language Students: A Professional Development Opportunity Through Action Research
}

Raj Khatri

This action research project empirically evaluated the efficacy of reading strategy instruction to help advance adult English as an additional language (EAL) students' development of academic reading skills and strategy use. The study involved 16 adult participants attending English for Academic Purposes (EAP) programs in British Columbia. These participants received reading strategy instruction over nine sessions during a 6-week period. To capture participants' reading strategy use, Mokhtari and Sheorey's Survey of Reading Strategies instrument was used in the pre-and post-intervention stages. Similarly, to measure participants' reading comprehension abilities, an identical, standardized reading comprehension test was administered in the pre-and post-intervention stages. Participants' weekly post-task verbal reflections and post-intervention interviews provided qualitative data for the study. Findings showed that reported reading strategy use obtained from the instrument and reading performance increased significantly after the intervention. The results from the analysis of participants' reflections and interviews revealed a positive association between participants' strategy use and reading performance. Conducted as a part of professional development, this study aims to resolve EAP professionals' practical concerns about the use of reading strategies in academic reading as well as provide action researchers with suggestions for future implementation.

Ce projet de recherche-action a permis d'effectuer une évaluation empirique de l'efficacité de l'enseignement de stratégies de lecture afin de faire avancer le développement des compétences académiques de lecture et du recours aux stratégies de lecture chez les étudiants adultes inscrits à un cours d'anglais comme langue additionnelle. Ont participé à l'étude 16 adultes inscrits à des programmes d'anglais académique en Colombie-Britannique. Ces participants ont pris part à neuf séances d'enseignement de stratégies de lecture sur une période de 6 semaines. L'instrument de mesure Reading Strategies de Mokhtari et Sheorey a été utilisé pour évaluer le recours des participants aux stratégies de lecture avant et après la période d'intervention. Un test identique et standardisé de compréhension de la lecture a également été administré avant et après la période d'intervention afin d'évaluer les capacités de compréhension des participants. Les réflexions verbales 
offertes par les participants après les exercices et les entrevues réalisées après l'intervention ont produit des données qualitatives pour l'étude. Celle-ci a permis de constater un accroissement significatif du recours aux stratégies de lecture fournies par l'instrument et de la performance de lecture suite à l'intervention. Les résultats de l'analyse des réflexions et des entrevues des participants ont permis de constater une association positive entre l'utilisation de stratégies de lecture et la performance de lecture des participants. Menée dans le cadre du perfectionnement professionnel, cette étude vise à répondre aux inquiétudes pratiques des professionnels de l'enseignement de l'anglais académique relativement au recours aux stratégies de lecture tout en fournissant aux praticiens et praticiennes de la recherche-action des suggestions à mettre en cuvre dans le futur.

KEYWORDS: reading strategy instruction, academic reading, adult EAL students, action research

The enrolment of international students in Canadian colleges and universities is increasing every year. A total of 221,862 international students joined Canadian institutions of higher learning in 2015-2016, an increase from 215,496 in 2014-2015 and 193,209 in 2013-2014 (Statistics Canada, 2018). The increase in the number of students from around the globe carries with it not only an extraordinary learning opportunity, but also challenges for both instructors and students (Ryan \& Carroll, 2005). To support this growth, it is essential that institutions of higher learning provide high-quality instruction that caters to the academic needs of these students. Among the many interconnected areas, one academic area where these students will need support is reading (Huang, 2010a). As an English for Academic Purposes (EAP) practitioner and researcher, who has specifically had concerns about teaching reading strategies and its efficacy on students' reading performance in my classes, I embraced action research as an opportunity to explore adult English as an additional language (EAL) students' reading in academic contexts. Therefore, I carried out the present mixed-methods research project within an action research framework to provide solutions to my personal classroom issues on the use of reading strategies among adult EAL students, as well as offer suggestions to action researchers who may have similar pedagogical concerns on second language (L2) reading strategies.

\section{Literature Review}

Learner strategy use, as Lei and Liu (2018) investigated through their bibliometric analysis, is one of the most extensively explored topics over the last 45 years. Specifically, their analysis showed that research of reading strategy and reading comprehension has been ongoing for the past 4 decades. Reading strategies refer to mental plans and actions that readers employ to solve read- 
ing problems and facilitate their understanding of the text (e.g., Brantmeier, 2002; Grabe, 2009; Hudson, 2007; Mokhtari \& Sheorey, 2008). Afflerbach, Pearson, and Paris defined reading strategies as "deliberate, goal-directed attempts to control and modify the reader's efforts to decode text, understand words, and construct meanings out of text" (2008, p. 15). In short, reading strategies are operations or behaviours that readers consciously employ to understand the text in context.

For learners to read and comprehend what they read, a variety of reading strategies have been identified. Among these strategies, readers may use cognitive strategies, which include manipulation of materials through guessing meaning from the context, making predictions, translating, summarizing, and connecting with prior knowledge and experience; readers may also use metacognitive strategies, which are associated with readers' regulation of themselves and may include planning, monitoring, and evaluating (e.g., Anderson, 2002; Grabe, 2009; O'Malley \& Chamot, 1990; Oxford, 1990; Oxford \& Crookall, 1989; Phakiti, 2006). Block (1992) defined metacognitive strategies as readers' use of their thinking and questioning process about their own plans and actions when engaged in reading activities. Mokhtari and Sheorey (2002) considered metacognitive strategies as mental actions or plans when reading academic materials, such as textbooks, journal articles, and class notes.

\section{Importance of Reading Strategy Use}

There is a wide consensus that the use of a variety of reading strategies helps adult EAL students develop their reading comprehension. Carrell (1998) posited that reading strategies play a vital role in reading comprehension. Similarly, Allen (2003) asserted research consistently showed that using strategies greatly enhanced comprehension of the written word. Evans's (2008) study of 22 first-year students who were also enrolled in an English-language program found metacognitive strategies useful both for reading comprehension and reading-to-write activities. Proficient readers used both cognitive and metacognitive strategies (Mokhtari \& Sheorey, 2008; Phakiti, 2006). Studies have shown that reading improves a reader's vocabulary, grammar, and reading comprehension, and that using strategies when reading leads to improved reading comprehension (Anderson, 1991; Grabe \& Stoller, 2011; Hudson, 2007; Mokhtari \& Sheorey, 2008). Anderson (1991) stated that it is important for L2 readers not only to know what strategy they have to use, but also to know how to use these strategies and orchestrate their use with other strategies, which is also clearly emphasized in Alhaqbani and Riazi's (2012) study. When readers become aware of the reading strategies they have already identified, their conscious decision to use particular strategies helps in comprehending the text (Akkakoson, 2012). 


\section{Studies on Reading Strategy Use}

Several studies on $\mathrm{L} 2$ reading comprehension have been undertaken, and the areas of interest as well as methods vary from researcher to researcher. In Anderson's (1991) study, 28 Spanish-speaking adult English as a second language (ESL) students' individual difference in strategy use was studied when these learners were engaged in reading in two contexts: reading for a standardized reading comprehension test and reading academic texts. The results suggested that not a single set of processing strategies existed to significantly contribute to participants' success on two reading tests. The participants scoring high and those scoring low seemed to have used the same kind of strategies, which may suggest that readers must know: what strategies to use and how.

A qualitative investigation in Li and Munby's (1996) study on ESL students' use of metacognitive strategies in their academic reading at the graduate level showed that participants varied their strategies depending upon reading assignments and purposes. The study also supported past research in which using metacognitive strategies helped ESL students advance in their academic settings.

In recent years, researchers employed Mokhtari and Sheorey's (2002) Survey of Reading Strategies (SORS) instrument to explore the reading strategy awareness among adult EAL students. Global strategies, problem-solving strategies, and support strategies are the three categories of reading strategies that the SORS measures. According to Mokhtari and Sheorey (2002), global strategies are the actions that readers carefully take to plan and monitor or manage their own reading. Reading with a purpose in mind, reviewing the text by noting its characteristics, such as length and organization, and reading the important and skipping the unimportant are a few of the individual strategies in this category. Problem-solving strategies include actions and procedures that readers employ to support or repair their comprehension. These are local, problem-solving techniques that readers incorporate when they encounter difficulties while trying to understand textual information. Adjusting speed, trying to get back on track when concentration is lost, and pausing and thinking about what is being read are a few of the strategies in this category. Support strategies are the tools that help readers in understanding the text. Taking notes while reading, underlining, or circling information, and paraphrasing are a few that belong to this category.

In a study on reading strategies in 2005, Poole compared the academic reading strategies of 248 (male $=138$, and female $=110$ ) advanced college ESL students in the United States. Mokhtari and Sheorey's (2002) SORS instrument was used to measure adult participants' self-perceived academic reading strategies. The results revealed no significant gender difference in participants' use of reading strategies. As postulated by the researchers, other 
factors, such as task demands, may have affected advanced ESL students' use of reading strategies.

In 2009, Malcolm investigated academic reading strategy use of 160 students at a medical university in Bahrain, using the SORS instrument. The results showed the students' overall reported strategy use was high. Significant differences were found in the students' use of strategies and their use of translation from English to Arabic.

Magogwe (2013) studied metacognitive reading strategies in relation to language proficiency of 104 first-year students at the University of Botswana. Incorporating the SORS and interviews, the researcher examined the students' self-reported reading strategy use. The results showed that the students reported high reading proficiency and high use of reading strategies.

In a study carried out on 122 undergraduate L2 Arabic students' use of strategies in reading academic texts in Arabic, Alhaqbani and Riazi (2012) found that problem-solving strategies were the most preferred, which was followed by global and support strategies. It was revealed that students who had studied at university longer reported more awareness of the use of reading strategies in all three strategy categories.

\section{Efficacy of Reading Strategy Instruction}

Several researchers have studied strategy instruction and its effects on learners' language learning in different contexts (Cohen \& Macaro, 2007; Macaro, 2001; Plonsky, 2011). As Dörnyei (2005) pointed out, through strategy instruction, language learners can avail themselves of opportunities to be aware of and practice different strategies in their language learning process. In her study, Barnett (1988) found a positive relationship between the perceived strategy use and reading comprehension, as well as the relationship between actual strategy use and reading comprehension. Kern (1989) indicated that reading strategy instruction had a strong positive effect on students' reading comprehension scores and on their ability to infer the meanings of unfamiliar words from context. In a study conducted at a Turkish technical university, Salataci and Akyel (2002) found a positive effect of reading strategy instruction on reading comprehension both in English and Turkish and English reading strategies. In an action research study, Küçükoğlu (2013) implemented reading strategy instruction among 14 students enrolled in an intermediatelevel integrated skills course at a university in Turkey. As in previous studies, the results demonstrated that instruction on strategies, such as predicting, visualizing, making connection, questioning, inferring, and summarizing, played a crucial role in helping students improve their reading comprehen-

sion. Similarly, a recent meta-analysis conducted by Chaury (2015) showed an overall positive effect of reading strategy instruction on students' reading comprehension, as the students who received reading strategy instruction performed better in reading comprehension tests than those who did 
not. Whether strategy instruction has actually improved learners' language performance is not without its criticism, however, as research on strategy instruction varies from one context to another (Cohen, 2011). In addition to confirming strategy instruction's medium to large effects on reading comprehension and strategy use, a meta-analysis carried out by Plonsky (2011) on the effectiveness of strategy instruction also found that strategy instruction provides the most benefits when the instruction focuses on a few strategies at a time and when learners get the opportunities to use and practice strategies for a long period of time.

While most studies involved various methods of data collection, such as reading comprehension tests, interviews, and think-alouds, to measure reading strategy use and reading comprehension, few included data from participants' strategy use through their verbal reflections. Considering this, the present study incorporated the element of participants' reflection on their strategy use for reading performance. Historically, John Dewey (1933) is acknowledged as a key originator of the concept of reflection, and he considered reflection as "active, persistent and careful consideration of any belief or supposed form of knowledge in the light of the grounds that support it and the further conclusion to which it tends ..." (p. 6). Huang (2010b) claimed that the reflection process helps students strengthen their awareness to become more focused on their learning process and strategic behaviours. For this study, based on definitions from different scholars, reflection is defined as participants' active involvement in their thinking process, regarding the actions they would deliberately take when completing reading tasks and the actions they would incorporate if they were to do such tasks in future. The qualitative component of data derived from participants' reflective entries provides a fuller picture of their strategy use in the present study.

L2 reading research has shown that readers' awareness of strategy use is associated with reading performance, but limited research has addressed the efficacy of reading strategy instruction among adult EAL students' reading strategy use and their reading performance, especially in the Canadian context. The present action research project has filled this void, as participants

had opportunities to take classes on reading strategies, use different reading strategies during reading academic materials in class, respond to comprehension questions, reflect on their strategy use, and report strategies they used during class.

\section{Research Questions}

The present research study was designed to address the following research questions:

Research Question 1 (RQ1): What are the strategies EAL students use when reading academic texts, as reported through the SORS 
instrument and students' post-task reflections and post-intervention interviews?

Research Question 2 (RQ2): What are the differences in pre- and post-intervention reading comprehension test scores and reported reading strategy use, as measured through the SORS instrument?

Research Question 3 (RQ3): What are the relationships in students' reading strategy use and reading comprehension test scores before and after the intervention?

\section{Method}

\section{Research Design}

To answer the research questions, concurrent mixed-methods action research (MMAR; Ivankova, 2015) was incorporated. The purpose of using the mixedmethods research design was to address the research questions from multiple perspectives, and draw enriched conclusions within an action research framework (Ivankova \& Kawamura, 2010). As a research methodology, action research enables practitioners to intervene deliberately in the area that needs attention and to generate changes and solutions in practice (Burns, 2010). The present study, adapted from Ivankova's (2015) action research model, emphasizes the systematic implementation of action research, especially mixed-methods action research. At the same time, as Huang (2012) posited, "the way we approach action research needs to be reconsidered" (p. 17). The questions that represent "real world pedagogical issues" (Huang, 2012, p. 17) are crucial to the implementation of action research. The research questions in the present study emerged from my teaching adult EAP classes and led me toward using a planned and systematic approach to action research. I was motivated, as Stringer (2014) suggested, to systematically conduct action research that would help address pedagogical concerns that I encounter in my teaching contexts. While I acknowledge that real classrooms are dynamic and even messy at times, and classroom teachers may not have sufficient time to implement such action research systematically, I wanted to engage in a study that is scientifically rigorous and that would help me examine my pedagogical interests in a credible way. According to Burns (2005), regarding action research (AR), the

action component involves participants in a process of planned intervention, where concrete strategies, processes or activities are developed within the research context ... the research element of AR involves the systematic collection of data as planned interventions are enacted ... (pp. 58-59) 
While as an instructor I performed the action part of the current AR project, I wanted to ensure that the research part of AR reflects research in its scientific meaning. Therefore, using mixed methods in an AR framework, I adopted five specific stages from Ivankova's (2015) MMAR: diagnosing, reconnoitering, planning, acting, and evaluating, with each stage influencing change-actions for the following stage. During the diagnosing stage, I collected from participants their background information, reported strategy use through the SORS, and responses to the pre-intervention Reading Comprehension (RC) test. These data were then analyzed, and a preliminary assessment of participants' strategy use was generated in the reconnaissance stage. In the planning stage, an intervention plan was developed, using the meta-inferences from the earlier stage. The intervention study was implemented over the next 6 sessions during the acting stage. I gathered participants' post-task verbal reflections during each session in this stage. In the evaluating stage, I collected participants' post-intervention reported strategy use through the SORS and their responses to the post-intervention RC test and the interviews.

\section{Participants}

The study involved 16 EAL students enrolled in EAP classes in British Columbia: 4 males and 12 females. In the study, each participant was assigned a code to safeguard their anonymity and confidentiality. Participants' characteristics according to their age group are presented in Table 1.

Table 1

Participant Characteristics

\begin{tabular}{lll}
\hline \multirow{2}{*}{ Gender } & Male & $4(25 \%)$ \\
& Female & $12(75 \%)$ \\
\hline First languages & Japanese (5), Mandarin (4), & \\
& Spanish (3), Korean (1), Thai (1), & \\
& Hindi (1), Russian (1) & \\
\hline Reported English proficiency & Intermediate (8), Advanced (8) & \\
\hline Age & Mean & 30.5 \\
& Range & $21-40$ \\
\hline English-language learning & Mean & 8.97 years \\
& Range & $2-15$ years \\
\hline Time spent per week in reading academic texts in English & Mean & $7.69 \mathrm{hr}$ \\
& Range & $1-30 \mathrm{hr}$ \\
\hline
\end{tabular}

\section{Intervention}

Reading strategy instruction classes were held twice a week for 6 weeks. Each session lasted $90 \mathrm{~min}$. The topics covered during the intervention included reading strategies, international students and their challenges, noise and its 
causes and effects, crop-growing skyscrapers, languages and their importance, transport in the past and the present, cigarette smoking and its risks. These topics were chosen to consider the interests of the many participants who represented different fields of study. A total of 30 reading strategies, as provided in the SORS, were introduced and explicitly taught on the first day of class. Participants and I also discussed when these strategies could be incorporated: before, during, or after reading the text. In addition, when engaged in reading, participants worked on these strategies during each of the intervention sessions throughout the study. During each reading task, for comprehension to take place, participants were encouraged to use different reading strategies from the SORS. Using think-alouds, as the instructorresearcher, I incorporated instructional scaffolding-modeled the reading strategy use for participants on several occasions during the study period. We performed shared reading, and participants sometimes carried out guided reading and, at other times, individual reading as well as reading in pairs. Then, participants practiced the reading strategy use and applied it to their reading.

\section{Data Collection Instruments}

(a) Background Information Sheet: This instrument elicited from participants some specific information, including their educational background, age, and time spent in English-language learning (refer to Table 1).

(b) The SORS: Mokhtari and Sheorey's (2002) SORS instrument was designed to measure adult EAL students' awareness of reading strategies when reading academic texts. The SORS is divided into three categories: global strategies (GLOBs), problem-solving strategies (PROBs), and support strategies (SUPs). The instrument has 30 items in total: The GLOBs has 13 items; the PROBs has 8 items; and the SUPs has 9 items. Each of the items is rated based on a 5-point Likert-type scale that ranges from 1 to $5(1=$ never or almost never used; $2=$ occasionally used; $3=$ used sometimes or about $50 \%$ of the time; $4=$ usually used; and $5=$ always or almost always used a strategy). Scoring a mean average of 3.50 or higher means a high usage of strategies; mean scores of 2.50 to 3.49 indicate a medium usage; and a mean score of 2.49 and below denotes a low usage. Mokhtari and Sheorey reported the SORS with a Cronbach's alpha of .89 reliability score.

(c) RC Tests: The study included two sets of RC Tests. Those passages were taken from the past official, academic International English Language Testing System (IELTS) examination papers published by the University of Cambridge Examinations. The purpose of including an additional set was to ensure that if a participant had previously used one set of RC tests, he or she would be assigned another set of the test. Because participants may use different reading strategies for different reading passages, the identical set of RC tests was used as the pre- and post-intervention reading comprehension test 
to measure participants' reading performance. The RC tests contained two passages and 26 questions. Reading passages contained a variety of questions that included a number of task types. There were different question types, such as multiple choice, identifying the writer's views or claims, matching information, matching headings, sentence completion, and short-answer questions.

(d) Post-Task Guided Verbal Reflections: The reflections included six questions (see Table 2) that were based on Anderson et al.'s (2001) revised Bloom's taxonomy for learning and were adapted from Huang (2013a) to elicit participants' thinking as well as their use and awareness of reading strategies when reading academic texts. At the end of each class, participants had $10 \mathrm{~min}$ to audio-record their response to the reflection questions. On the first day of class, I modeled the audio-recording process as part of the responses to the post-task guided verbal reflection questions (refer to Table 2) using a digital voice recorder. Individual participants were then given a recorder, and they had the opportunity to practice. They were also allowed to write their responses to the questions using only keywords to facilitate their recording. They then audio-recorded the responses. At the end of each class, I collected the recorders and transcribed them for data analysis.

Table 2

Post-Task Guided Verbal Reflection Questions

\begin{tabular}{ll}
\hline Remembering & What did I do before I began to read the text today? \\
Understanding & What challenges did I find while reading the text? \\
Applying & Which strategies did I use? Will I use them again in my future reading? \\
Analyzing & Among the strategies I used today, what worked and what didn't? \\
Evaluating & What will I do differently when reading the text next time? \\
Creating & What other reading strategies can I experiment with to overcome my \\
& reading challenges? \\
\hline
\end{tabular}

(e) Post-Intervention Interviews: A week after the post-intervention RC test was administered, a semistructured interview was conducted with each of the participants, which gave me an in-depth understanding of their reading processes, as they read. The interview consisted of a reading task with two associated questions and five additional questions on participants' reading strategy use. For the reading part of the interview, participants were asked to read the first two paragraphs from an academic text. They were then asked to perform think-alouds, during which they verbalized their thinking process, and they were encouraged to perform the reading task as they would normally do. Think-aloud is a "widely used method to elicit and vocalize what is happening in the mind of an individual" (Ghavamnia, Ketabi, \& Tavakoli, 2013 , p. 8). As strategies are "deliberate thoughts and behaviours" learners incorporate to perform cognitive processes in order to complete tasks" 
(Huang 2013b, p. 5), participants' thoughts expressed through think-alouds helped me elicit participants' actual strategy use while performing the reading task.

\section{Data Collection Procedure}

In week 1 , participants were first informed of the nature, the purpose, and the procedure of the study. They were also given what they would be expected to do during the study. The study followed the established institutional ethical protocol. Participants were asked to provide their informed consent to participate in the study.

All participants were then asked to complete the Background Information Sheet in week 1 . Afterward, they filled out the SORS, which took 20 min on average. Finally, for the next $40 \mathrm{~min}$, participants took the pre-intervention $\mathrm{RC}$ test. Starting week 2, for $10 \mathrm{~min}$ toward the end of each of the 6 sessions, participants were asked to audio-record their responses to the post-task guided verbal reflection questions. In week 5, participants again completed the SORS and the post-intervention RC test. In week 6 , all participants were individually interviewed for $15 \mathrm{~min}$.

\section{Data Analysis}

Using an MMAR design, this study involved triangulation of quantitative and qualitative data. To answer RQ1, the data from the SORS were analyzed, and descriptive statistics were calculated, using IBM SPSS Statistics Version 24. In addition, the recordings from participants' post-task verbal reflections and post-intervention interviews were fully transcribed. All the transcripts were then carefully analyzed, using content analysis. Drawing on Mokhtari and Sheorey's (2002) strategy classification on the SORS, data were coded to obtain participants' reading strategy use. Strategies were identified, and by calculating descriptive statistics, the total frequency of strategy use was obtained to respond to the first research question.

To address RQ2, paired-sample $t$ tests were used to analyze the data from the pre- and post-intervention RC tests as well as pre- and post-intervention SORS scores.

To answer RQ3, Pearson's correlation was run to examine the relationship of the RC test scores with reading strategy use from the post-intervention SORS scores and reading strategy use from participants' post-task reflections and post-intervention interviews. The mean values from the SORS and from the reflections and the interviews are not comparable, as they were obtained in two different ways. While the SORS is based on a 5-point Likert-type scale, mean values reflect the data from the reflections and the interviews. As the instructor-researcher, I identified all individual strategies participants reported during their post-task guided verbal reflections and the post-inter- 
vention interviews. Then I prepared a frequency chart that reflected the number of times a particular strategy was repeated by each participant during the reflections and the interviews. The mean values for the GLOBs, the PROBs, and the SUPs were obtained by dividing the total GLOBs, PROBs, and SUPs strategy use counts by 13,8 , and 9 , as there were 13 GLOBs, 8 PROBs, and 9 SUPs.

\section{Results and Discussion}

When answering research questions, the quantitative results are presented first. The results from the analysis of the qualitative data obtained from the participants' post-task verbal reflections and post-intervention interviews are then integrated.

RQ1: What are the strategies EAL students use when reading academic texts, as reported through the SORS instrument and students' post-task verbal reflections and post-intervention interviews?

To address RQ1, descriptive statistics were performed. In the pre-intervention, the overall strategy use (OVERALL) was reported in the high-usage category $(M \geq 3.50)$, as presented in Table 3. Category-wise, PROB strategies were reported in the high-usage category $(M \geq 3.50)$ whereas GLOB strategies and SUP strategies were in the medium usage $(2.50 \leq M \leq 3.40)$. These results are consistent with some previous studies that also employed the SORS to measure adult ESL students' strategy use (e.g., Magogwe, 2013). However, in Alhaqbani and Riazi's (2012) study, the overall strategy use as well as the GLOB, the PROB, and the SUP strategy use were reported in the high-usage category. The order of preference for strategy category remains the same as those reported in some other studies (e.g., Alsheikh, 2011; Maasum, \& Maarof, 2012; Mokhtari \& Sheorey, 2008; Yüksel \& Yüksel, 2012): The PROB category was the most preferred, followed by the GLOB and the SUP category.

Regarding the post-intervention reported strategy use in Table 3, the overall strategy use as well as the GLOB, the PROB, and the SUP strategy use are in the high-usage category. The overall reported strategy use has increased from the pre-intervention $(M=3.42, S D=0.53)$ to the post-intervention $(M=4.00, S D=0.34)$. Likewise, the GLOB, the PROB, and the SUP strategy categories all increased in the post-intervention. 
Table 3

Descriptive Statistics for Reported Strategies: Overall and by Category

\begin{tabular}{|c|c|c|c|c|c|c|c|c|c|}
\hline \multirow[b]{2}{*}{ Category } & \multicolumn{6}{|c|}{ SORS } & \multicolumn{3}{|c|}{$\begin{array}{c}\text { Reflections and Interviews } \\
\text { Post-Intervention }\end{array}$} \\
\hline & $M$ & $S D$ & Rank & $M$ & $S D$ & Rank & $M$ & $S D$ & Rank \\
\hline OVERALL & 3.42 & 0.53 & & 4.00 & 0.34 & & 2.73 & 0.19 & 3 \\
\hline GLOB & 3.33 & 0.65 & 2 & 4.08 & 0.35 & 2 & 2.03 & 0.26 & 3 \\
\hline SUP & 3.11 & 0.60 & 3 & 3.63 & 0.58 & 3 & 2.88 & 0.35 & 2 \\
\hline
\end{tabular}

Note $. \mathrm{GLOB}=$ Global Strategy; $\mathrm{PROB}=$ Problem-Solving Strategy; SUP = Support Strategy.

The descriptive statistics of participants' strategy use in the post-task verbal reflections and post-intervention interviews identified 30 individual strategies, with the total frequency of 1,308 . The total frequency for the GLOB, the PROB, and the SUP strategy were 423 (32.34\%), 470 (35.93\%), and 415 $(31.73 \%)$, respectively. The results from the reflections and the interviews in Table 3 also show that PROBs were most highly used by participants.

The high usage of the overall reported strategy use from the SORS aligns with some previous studies (e.g., Magogwe, 2013; Malcolm, 2009; Mokhtari \& Sheorey, 2002). Such a high awareness of the overall strategies in the present study may indicate that this particular group of participants was highly engaged in reading strategies.

Table 4 presents the five most and five least reported individual strategy use reported by participants in the pre-intervention. When they "lost concentration in the midst of reading academic materials, participants tried to get back on track," which was the most reported strategy among these participants. As participants also asserted in their interviews, they "re-read the text to enhance their understanding of the textual information," and they were "very careful about their reading speed." At the same time, some participants did not attempt to "read aloud often when it was difficult for them to comprehend texts," which was the least reported strategy.

Table 4

Five Most and Five Least Reported Strategies in the Pre-Intervention

\begin{tabular}{llll}
\hline Strategy Item & Five Most Reported Strategies & $M$ & $S D$ \\
\hline PROB 9 & I try to get back on track when I lose concentration. & 4.44 & 0.73 \\
PROB 25 & $\begin{array}{l}\text { When text becomes difficult, I re-read it to increase } \\
\text { my understanding. }\end{array}$ & 4.44 & 0.81 \\
PROB 11 & I adjust my reading speed according to what I am & 4.31 & 1.08 \\
reading. & & \\
SUP 13 & $\begin{array}{l}\text { I use reference materials (e.g., a dictionary) to help } \\
\text { me understand what I read. }\end{array}$
\end{tabular}




\begin{tabular}{llll} 
Strategy Item & Five Most Reported Strategies & $M$ & \multicolumn{1}{c}{$S D$} \\
\hline PROB 7 & $\begin{array}{l}\text { I read slowly and carefully to make sure I } \\
\text { understand what I am reading. }\end{array}$ & 4.19 & 1.05 \\
\hline \multicolumn{1}{c}{$\quad$ Five Least Reported Strategies } \\
\hline SUP 5 & $\begin{array}{l}\text { When text becomes difficult, I read aloud to help } \\
\text { me understand what I read. }\end{array}$ & 2.06 & 1.12 \\
SUP 26 & $\begin{array}{l}\text { I ask myself questions I like to have answered in } \\
\text { the text. }\end{array}$ & 2.06 & 1.06 \\
I check to see if my guesses about the text are & 2.69 & 1.14 \\
GLOB 27 & $\begin{array}{l}\text { right or wrong. } \\
\text { I critically analyze and evaluate the information } \\
\text { GLOB 21 }\end{array}$ & 2.75 & 1.13 \\
GLOB 8 & $\begin{array}{l}\text { I review the text first by noting its characteristics } \\
\text { like length and organization. }\end{array}$ & 2.75 & 1.24 \\
\hline
\end{tabular}

Note. GLOB = Global Strategy; PROB = Problem-Solving Strategy; SUP = Support Strategy.

Table 5

Five Most Reported Strategies in the Post-Intervention

\begin{tabular}{|c|c|c|c|}
\hline Strategy Item & SORS & M & $S D$ \\
\hline SUP 10 & $\begin{array}{l}\text { I underline and circle information in the text to } \\
\text { help me remember it. }\end{array}$ & 4.81 & 0.54 \\
\hline PROB 14 & $\begin{array}{l}\text { When text becomes difficult, I pay closer attention } \\
\text { to what I am reading. }\end{array}$ & 4.75 & 0.59 \\
\hline PROB 25 & $\begin{array}{l}\text { When text becomes difficult, I re-read it to increase } \\
\text { my understanding. }\end{array}$ & 4.69 & 0.48 \\
\hline GLOB 1 & I have a purpose in mind when I read. & 4.63 & 0.62 \\
\hline \multirow[t]{2}{*}{ PROB 11} & $\begin{array}{l}\text { I adjust my reading speed according to what I am } \\
\text { reading. }\end{array}$ & 4.50 & 0.82 \\
\hline & Reflections and Interviews & M & $S D$ \\
\hline SUP 10 & $\begin{array}{l}\text { I underline and circle information in the text to } \\
\text { help me remember it. }\end{array}$ & 5.63 & 0.81 \\
\hline GLOB 1 & I have a purpose in mind when I read. & 4.81 & 0.91 \\
\hline GLOB 4 & $\begin{array}{l}\text { I take an overall view of the text to see what it is } \\
\text { about before reading it. }\end{array}$ & 4.75 & 1.06 \\
\hline GLOB 8 & $\begin{array}{l}\text { I review the text first by noting its characteristics } \\
\text { like length and organization. }\end{array}$ & 4.69 & 1.08 \\
\hline PROB 9 & I try to get back on track when I lose concentration. & 4.63 & 1.41 \\
\hline
\end{tabular}

Note. GLOB = Global Strategy; PROB = Problem-Solving Strategy; SUP = Support Strategy.

However, the pattern of the most reported strategies changed in the post-intervention strategy use from the SORS as well as from the post-task reflections and the interviews. Table 5 shows that GLOB 1 and SUP 10 in 
bold are common strategies. Participants had a purpose when they read the texts in class, and they underlined and circled information in the text so that they would remember the information. PROB 11, PROB 14, and PROB 25 were also mentioned as the most reported strategies in the SORS, but these strategies were not among the most reported strategies in the reflections and interviews. However, they were still used with high frequency by participants when reading academic texts (PROB 11: $M=4.19, S D=1.17$; PROB 14: $M=4.56, S D=1.09$; and PROB 25: $M=4.00, S D=0.89$ ). This particular group of participants seemed to be aware of reading strategies, and the data from the SORS and the reflections and interviews reflected that they were able to use strategies that they were aware of.

During their reflections and interviews, participants repeatedly mentioned the importance of having a purpose in mind when reading academic texts (GLOB 1) as well as that of underlining and circling key words (SUP 10). For example, one of the participants acknowledged that she underlined some words that she thought would be somewhat important and circled the ones that she thought would express key ideas in the text central to her understanding of the text. Similarly, participants expressed that they took note of the overall viewpoint of the text (GLOB 4) as well as the length and structure of the text before they began to read the text (GLOB 8).

Participants reiterated that they attempted to predict the content in the text, based on the title and subtitle of the text, in addition to skimming the comprehension questions and the first and the last paragraphs (GLOB 4; GLOB 24). A total of 14 participants (87.50\%) asserted that they tried to locate the main idea or thesis statement of the text as well as topic sentences to know more about the given text. Overall, participants' use of these strategies in this study is consistent with previous studies (e.g., Li \& Munby, 1996). When participants did not understand the text or lost concentration, they reread part of the text (PROB 25) and, thus, tried to get back on track (PROB 9). Participants also talked about brainstorming and linking key words from the text with their life experiences. As illustrated by participant RS08, for example,

I read the title of the text and I briefly glanced at questions and exercises after the text. And, I tried to estimate the level of the difficulty and the text and the length and vocabulary. I used different strategies for easy text.

The same participant, in response to a question on a different text, reported,

First of all, I scanned the text. I read twice the title. Then I went through sub-titles, reading them with attention. Then I was trying to understand the main idea based on the sub-title and the structure. And, then I started reading. But my previous knowledge of the story helped to understand the text well. 
This excerpt shows that this participant used pre-reading strategies and attempted to activate her schemata by making connections between her past knowledge and her reading. Some participants claimed that they did not have any challenges when the text was very easy to read, so they did not have to use strategies to comprehend simple texts. Alternatively, they incorporated different strategies when they encountered complex texts. For eight participants $(50 \%)$, being able to identify contexts in the text made the text easy, but they found texts with long, complex sentences and new vocabulary items very difficult to understand. In cases of such difficult-to-understand texts, these participants reported that they relied on various strategies, such as drawing pictures or structures to represent the text content, and guessing the meaning from the context or from the use of conjunctions or adverbials in context. Although some complex sentences were difficult for participants to comprehend, the use of conjunctions, as participants claimed, helped them at least to distinguish, according to the context, which clause was a cause or effect (because of the use of "because") or which sentences consisted of opposing views, as "however" connects two opposing ideas.

As the participants were asked to read and perform think-alouds during the interview, I was able to validate some of the reading strategies used by participants. During their think-alouds, participants were observed to have used various strategies, such as underlining and circling key words, writing marginal notes, using question marks and revisiting underlined phrases, rereading sentences, asking themselves questions on whether they really understood what they read, trying to guess the meaning from the context, and going back and forth in the text.

Table 6

Five Least Reported Strategies in the Post-Intervention

\begin{tabular}{|c|c|c|c|}
\hline Strategy Item & SORS & $M$ & $S D$ \\
\hline SUP 29 & $\begin{array}{l}\text { When reading, I translate from English into my } \\
\text { native language. }\end{array}$ & 2.75 & 1.34 \\
\hline SUP 30 & $\begin{array}{l}\text { When reading, I think about information in both } \\
\text { English and my mother tongue. }\end{array}$ & 2.93 & 1.44 \\
\hline SUP 5 & $\begin{array}{l}\text { When text becomes difficult, I read aloud to help } \\
\text { me understand what I read. }\end{array}$ & 3.06 & 1.24 \\
\hline SUP 26 & $\begin{array}{l}\text { I ask myself questions I like to have answered in } \\
\text { the text. }\end{array}$ & 3.44 & 1.15 \\
\hline \multirow[t]{2}{*}{ GLOB 6} & $\begin{array}{l}\text { I think about whether the content of the text fits } \\
\text { my reading purpose. }\end{array}$ & 3.63 & 0.96 \\
\hline & Reflections and Interviews & $M$ & $S D$ \\
\hline GLOB 6 & $\begin{array}{l}\text { I think about whether the content of the text fits } \\
\text { my reading purpose. }\end{array}$ & 0.38 & 0.62 \\
\hline
\end{tabular}




\begin{tabular}{llll} 
Strategy Item & SORS & $M$ & $S D$ \\
\hline GLOB 20 & $\begin{array}{l}\text { I use typographical features like bold face and } \\
\text { italics to identify key information. }\end{array}$ & 0.69 & 0.60 \\
GLOB 27 & $\begin{array}{l}\text { I check to see if my guesses about the text are } \\
\text { right or wrong. }\end{array}$ & 0.69 & 0.60 \\
GLOB 21 & $\begin{array}{l}\text { I critically analyze and evaluate the information } \\
\text { presented in the text. }\end{array}$ & 0.75 & 0.58 \\
GLOB 23 & $\begin{array}{l}\text { I check my understanding when I come across } \\
\text { new information. }\end{array}$ & 0.81 & 0.75 \\
\hline
\end{tabular}

Note. $\mathrm{GLOB}=$ Global Strategy; $\mathrm{PROB}=$ Problem-Solving Strategy; SUP = Support Strategy.

Table 6 shows the least reported individual strategies, first from the SORS and then from the participants' post-task reflections and post-intervention interviews. Only GLOB 6 in bold is a common strategy. While this particular group of participants reported using their native language (SUP 29 and SUP 30) least, it was not corroborated in their actual use of strategies when reading academic texts in class. Instead, participants employed SUP $29(M=$ $3.38, S D=1.03)$ and SUP $30(M=2.44, S D=0.96)$ to a large extent during their reading in class, which was further corroborated during the post-intervention interviews.

Although participants reported some strategies frequently, there were other strategies that participants did not report often. Only four participants $(25 \%)$ reported once about whether what they were reading would fit their reading purpose (GLOB 6), and only nine participants $(56.25 \%)$ once mentioned using typographical features, such as words in bold or italics, during the entire intervention. However, there were not many words in bold or italics.

In addition to the 30 strategies in the SORS, 8 additional strategies were identified in the post-task guided verbal reflections and the post-intervention interviews. The total frequency for these strategies was 92 . These strategies included brainstorming $(n=5)$, skimming $(n=15)$, scanning $(n=23)$, making inferences $(n=4)$, drawing pictures or structures to understand the text $(n=2)$, reading comprehension questions before beginning to read the text $(n=11)$, determining the thesis statement $(n=14)$, and locating topic sentences $(n=18)$. While all 16 participants claimed they used the scanning strategy to determine the specific information in the text, 12 mentioned they tried to identify the main ideas of the unit or paragraph by locating the thesis statement or topic sentence. One of the participants mentioned that she drew pictures and structures to comprehend what she was reading, which would help her remember the particular part of the text when answering the comprehension questions later. 
RQ2: What are the differences in pre- and post-intervention reading comprehension test scores and reported reading strategy use, as measured through the SORS instrument?

A paired-sample $t$ test was conducted to determine the differences in pre- and post-intervention RC test scores and reported reading strategy use measured through the SORS. There was a significant difference in the postintervention $\mathrm{RC}$ test scores $(M=72.60, S D=11.49)$ and the pre-intervention $R C$ test scores $(M=53.37, S D=17.14), t(15)=5.87, p<.0005$.

In terms of strategy use, the overall strategy use was significantly higher for the post-intervention $(M=4.00, S D=0.34)$ than for the pre-intervention $(M=3.43, S D=0.53), t(15)=5.26, p<.005$, as presented in Table 7. Categorywise, participants reported higher use of GLOBs, PROBs, and SUPs in the post-intervention.

Table 7

Descriptive Statistics and $t$ Test Results for Reading Strategy Use

\begin{tabular}{|c|c|c|c|c|c|c|c|c|c|}
\hline & \multicolumn{2}{|c|}{ Pre-Intervention } & \multicolumn{2}{|c|}{ Post-Intervention } & \multirow[t]{2}{*}{$n$} & \multirow[t]{2}{*}{$\begin{array}{l}95 \% \mathrm{Cl} \\
\text { for Mean } \\
\text { Difference }\end{array}$} & \multirow[t]{2}{*}{$t$} & \multirow[t]{2}{*}{$d f$} & \multirow[t]{2}{*}{$p$} \\
\hline Strategies & $M$ & $S D$ & $M$ & $S D$ & & & & & \\
\hline OVERALL & 3.43 & 0.53 & 4.00 & 0.34 & 16 & $0.35,0.83$ & 5.26 & 15 & $.00^{*}$ \\
\hline GLOB & 3.33 & 0.65 & 4.08 & 0.35 & 16 & $0.47,1.03$ & 5.66 & 15 & $.00^{*}$ \\
\hline PROB & 3.91 & 0.54 & 4.30 & 0.39 & 16 & $0.11,0.69$ & 2.93 & 15 & $.01^{*}$ \\
\hline SUP & 3.11 & 0.60 & 3.63 & 0.58 & 16 & $0.28,0.77$ & 4.51 & 15 & $.00^{*}$ \\
\hline
\end{tabular}

Note. $\mathrm{Cl}=$ Confidence Interval; $\mathrm{df}=$ degrees of freedom; GLOB = Global Strategy; PROB = ProblemSolving Strategy; SUP = Support Strategy.

${ }^{*} p<.05$ (two-tailed $t$ test).

Participants, thus, performed statistically significantly better in the postintervention RC test, the overall reported strategy use, and in the use of GLOBs, PROBs, and SUPs, as measured through the SORS instrument. Participants' strategy use reported through the SORS and their RC test scores may demonstrate that these participants were not only aware of a variety of reading strategies but were also able to incorporate reading strategies when reading academic texts and providing responses to comprehension questions.

Data from participant RS08's reflections showed that she incorporated different strategies, depending on complexity of the text. During the reflection as well as the interview, she enhanced her ability to consciously think, reflect on, and make logical inferences from reading the text. Reflecting on their reading speed, five participants $(31.25 \%)$ repeatedly claimed they changed their reading speed to read the text slowly and carefully for their comprehension to take place effectively (PROB 11 and PROB 7). When there were several examples to support the main idea in a paragraph, four participants $(25 \%)$ 
went over the examples very quickly but paid closer attention to reading (PROB 11 and PROB 14) or rereading the main idea (PROB 25). For instance, in his post-task reflection, participant RS04 mentioned the following:

Today I scanned text. I underlined key ideas and topics [SUP 10]. I also re-read several paragraphs when I realized that it is difficult to get main idea [PROB 25] ... When the text was getting more difficult I was paying more attention [PROB 14]. And I was reading more carefully [PROB 7] ... When there were several examples for the same idea, I read one example and skipped the other [GLOB 12]. But I read and read the idea carefully [PROB 7].

When they were unable to construct meaning with support from the strategies they already used, participants turned toward applying other strategies. Among the nine participants who mentioned that they looked for words in bold and italics, four of them did not find information in bold or italics. As a result, they quickly turned to considering the strategies that would work and switched to scanning part of the text to comprehend the text and answer the questions that followed it. Participants were able to apply and switch strategies as per the demand of the text. Such use of strategies is a key metacognitive skill (Anderson, 2002). In addition, 13 of the participants (81.25\%) repeatedly found it useful to guess the meaning out of the context (PROB 28) in the beginning, rather than using dictionaries (SUP 13) right away. For example, the following narrative captures participant RS03's strategy use:

I kept reading the same paragraph about crops many times [PROB 25] because it was too difficult. But later I found that this didn't work. But I don't know when I started reading to myself loudly [SUP 5] and thinking about the text [GLOB 6]. Then I think I tried to make connections between what I was reading and what I already know about the text from the title and topic sentences overall [GLOB 4]. But I did this in my own language [SUP 29]. My grandfather was a farmer. I used to visit him far away. I knew farming from him. Words were difficult, but I knew from the context [PROB 28] mostly. I didn't look at the dictionary much at this time.

Three participants $(18.75 \%)$ also mentioned that depending upon the difficulty level of the texts, their reading strategies varied, which was also reported in studies previously conducted on adult EAL students' use of reading strategies (e.g., Li \& Munby, 1996). Seven participants (43.75\%) expressed that they started using more strategies than they used in the past. The following excerpt from participant RS01 illustrates this awareness:

I don't know maybe the more I read the more strategies I will be able to discover ... I use strategies more than I did. Now I try to draw some pictures of the main idea of the text before I read [GLOB 24]. 
RQ3: What are the relationships in students' reading strategy use and reading comprehension test scores before and after the intervention?

A Pearson's correlation test was performed to answer the third research question. As presented in Table 8, the relationship between the RC test scores and the reported strategy use from the SORS in the pre- and post-intervention and between the RC test scores and the strategy use from participants' posttask reflections and post-intervention interviews were assessed.

In the pre-intervention, a negative correlation was found between the overall strategy use and the RC test scores, $r=-.09, p=.74$. However, there was a positive correlation between the GLOB strategy use and the RC test scores, $r=.90, p=.01$, between the PROB strategy use and the RC test scores, $r=.88, p=.01$, and between the SUP strategy use and the RC test scores, $r=.84, p=.01$, all of which were statistically significant.

In the post-intervention, there was a positive correlation only between the PROB strategy use and the RC test scores, $r=.06$. This correlation was not statistically significant $(p=.81)$. A negative correlation was found between the overall reported strategy use and the RC test scores, $r=-.47, p=.07$, between the GLOB reading strategy use and the RC test scores, $r=-.35, p=.19$, and between the SUP strategy use and the RC test scores, $r=-.67, p=.01$.

Table 8

Pearson's Correlation between Reading Comprehension Test and Strategy Use

\begin{tabular}{|c|c|c|c|c|c|c|}
\hline & & & OVERALL & GLOB & PROB & SUP \\
\hline \multicolumn{7}{|l|}{ SORS } \\
\hline \multirow[t]{3}{*}{ Pre-Intervention } & RC Test & Correlation Coefficient & -.09 & $.90^{* *}$ & $.88^{* *}$ & $.84^{* *}$ \\
\hline & & Sig. (2-tailed) & .74 & .00 & .00 & .00 \\
\hline & & $N$ & 16 & 16 & 16 & 16 \\
\hline \multirow[t]{3}{*}{ Post-Intervention } & RC Test & Correlation Coefficient & -.47 & -.35 & .06 & -.67 \\
\hline & & Sig. (2-tailed) & .07 & .19 & .81 & $.00^{* *}$ \\
\hline & & $N$ & 16 & 16 & 16 & 16 \\
\hline \multicolumn{7}{|c|}{ Reflections and Interviews } \\
\hline \multirow[t]{3}{*}{ Post-Intervention } & RC Test & Correlation Coefficient & .38 & .16 & .38 & .16 \\
\hline & & Sig. (2-tailed) & .14 & .54 & .15 & .55 \\
\hline & & $N$ & 16 & 16 & 16 & 16 \\
\hline
\end{tabular}

Note. $\mathrm{RC}=$ Reading Comprehension; GLOB = Global Strategy; PROB = Problem-Solving Strategy; SUP = Support Strategy.

${ }^{* *} p<.01$ (two-tailed $t$ test).

Mokhtari and Sheorey (2002) emphasized triangulation of data, as ". . . SORS is a self-measure instrument, one cannot say with absolute certainty from the instrument alone whether students actually engage in the strategies they report using" (p. 6). Furthermore, as Zhou and Huang (2018) pointed 
out, ". . . relying solely on perceived strategy use elicited through general self-report measures of strategies and using non-task-, non-learner, and non-context-specific instruments deserve serious consideration" (pp. 17-18). Therefore, data from participants' post-task reflections and post-interviews that included the use of think-alouds were integrated in the present study, in addition to the data from the SORS. As shown in Table 8, the results from Pearson's correlation test demonstrate that the RC test scores had a positive correlation with the overall strategy use, $r=.38, p=.14$, the GLOB strategy use, $r=.16, p=.54$, the PROB strategy use, $r=.38, p=.15$, and the SUP strategy use, $r=.16, p=.55$.

Both in their reflections and interviews, participants provided their feedback on the opportunities to become aware of and use different reading strategies. They expressed that such opportunities heightened their awareness as well as regulation of strategies, enhanced their engagement with reading materials, and contributed to the development of their reading performance. Although GLOB 21-"critically analyzing and evaluating the information presented in the text" - significantly increased from the preintervention to the post-intervention as measured through the SORS, five participants $(31.25 \%)$ did not use this strategy at all based on the data from their reflections and interviews. During the interview, two of these participants acknowledged that they were not even aware of this strategy in the past, so they were appreciative of the opportunity to be able to incorporate such strategies, which they emphasized have helped them to become active, strategic readers.

The main goal of this study was to evaluate the efficacy of reading strategy instruction among adult EAL students. Participants reported an increase in the overall strategy use and strategy category in the post-intervention, as measured by the SORS, and the increase was statistically significant. In their reflections and interviews, most participants reiterated that their awareness and use of reading strategies have increased as a result of the intervention. In line with previous studies (e.g., Barnet, 1988; Salataci \& Akyel, 2002), the findings from the present study also indicated that the RC test scores and the reading strategy use are positively correlated. Reading strategy instruction in the present study seems to have helped participants to become aware of and apply different reading strategies, thereby enhancing their reading strategy use as well as their reading performance. Findings suggest that as reading academic texts is a complex task, it is important that, for comprehension to be effective, students be aware of different reading strategies, with frequent opportunities to practice those strategies, which also aligns with $\mathrm{Li}$ and Munby (1996). 


\section{Implications and Limitations}

Although the results of this study support the importance of reading strategy instruction among adult EAL students, the findings are limited in that the intervention period was short, and the instructor-researcher was the only coder coding reading strategies, which warrants further investigation in the field. By nature, findings of an AR study are not meant for generalization beyond instructor-researcher's specific research circumstances (Burns, 2010), as the focus of such studies is on addressing issues related to instructorresearcher's personal classroom. Although the results did not show a positive correlation between the $\mathrm{RC}$ test scores and the post-intervention overall strategy use measured through the SORS, there was a positive relationship between the RC test scores and the post-intervention overall strategy use obtained through participants' reflections and interviews. In addition, participants' positive voices on their reading performance as a result of the intervention cannot simply be dismissed. During their reflections and interviews, participants indicated that their heightened awareness and regulation of different reading strategies contributed to their becoming better readers in their academic milieu.

This study may be applicable to EAP practitioners who may have been facing challenges on $\mathrm{L} 2$ reading instruction in supporting their adult EAL students in reading comprehension. This work contributes to the existing body of literature on reading strategy instruction to help EAP practitioners make informed decisions about applying research-based pedagogies to facilitate the development of $\mathrm{L} 2$ reading.

As Mokhtari and Sheorey (2002) suggested, reading strategy instruction should be included in the reading curriculum, which can be instrumental in developing students' awareness of the process and the strategies involved in reading. Adult EAL students should be guided to develop their awareness of reading strategies. Then, students can consciously make decisions to use appropriate strategies, which may help them in their understanding of the text (Akkakoson, 2012).

Given the increasing number of EAL students at institutions of higher learning in Canada, the field may benefit from instructors carrying out their own ecologically valid AR projects on reading strategy use while developing students' reading comprehension in academic settings.

\section{Suggestions for Action Researchers}

In addition to transferability of the study's results to other contexts and settings in EAL communities where strategies may be elucidated and incorporated in intervention planning, the following suggestions may prove useful for action researchers working in academic reading: 
Researchers are encouraged to keep promoting reflective practices among participants and themselves during the entire study, as reflecting on practice greatly contributes to learning (McNiff, 2013). Participants' reflection on the strategy use during the interview in this study provided me with concrete evidences on the reading strategies that they used when reading an academic text provided.

At the same time, as an instructor and researcher, I found self-reflection a powerful tool in further developing my skills and knowledge in the process of supporting my students in their academic reading. My journal entries allowed me to reflect on my own teaching and prepare myself for the following session on the reading strategy instruction.

Participants must be motivated to collaborate and share their voices, to help them build a community (Mills, 2011) and be an integral part of the AR (Savin-Baden \& Major, 2013). In the beginning, some participants hesitated to take part in pair or group work or provide their reflections. However, it did not take long for them to realize that their participation and sharing of their thoughts on the reading strategy use not only helped them in their reading performance but they were also able to contribute to their peers' success and be an important part of this study.

It is useful in the process to learn from one's shortcomings. I sometimes planned my lessons on reading strategy instruction, without realizing that students may use different strategies for the same reading text. I planned to teach certain strategies useful for a particular text; however, students came up with different strategies from the SORS that were equally integral to their understanding of the text being discussed. This helped me learn that I needed to become more flexible in understanding the dynamic nature of my students' use of reading strategies, to help them explore and use different reading strategies during their reading. Again, self-reflection was instrumental to understanding my students' characteristics and planning my lessons for the following sessions on reading strategy instruction.

\section{Conclusion}

This project was part of my professional development, and its implementation was very challenging. First of all, I needed a considerable amount of time and effort to carry out the study. Moreover, bringing together all participants' actions and voices through their reflections was initially a slow and challenging process. It took some time to help participants understand their contribution to and their ownership of their learning as part of AR. However, they gradually learned to immerse in the process and contribute to the project through thoughtful discussions and reflective practices. Participants learned to collaboratively engage in the systematic exploration of reading strategies use, thus, "building the community of learners" (Mills, 2011, p. 7). 
The entire process has been rewarding at the same time. I am encouraged to carry out similar projects in future, including factoring in different variables, such as participants' proficiency levels and gender. I am able to make informed decisions on the implementation and efficacy of reading strategy instruction in the process of improving my teaching practices and supporting my students in their academic reading through reading strategy instruction. Working with participants in collaborative and reflective ways in the process has helped me to further develop professionally in the field.

\section{Acknowledgement}

I would like to thank two anonymous reviewers for their insightful comments and suggestions. I am also grateful to Dr. Li-Shih Huang for her guidance and motivation during the implementation of the study. As well, thanks are due to students who generously provided their time for the study.

\section{The Author}

Raj Khatri is a PhD candidate and TESL practicum supervisor at the Department of Linguistics of the University of Victoria. His areas of interest include L2 reading and writing, L2 reading strategies, taskbased learning, and adult EAL learners with disabilities. Accredited member of TESL Canada and Ontario College of Teachers, Raj has taught EAP classes for more than 15 years at institutions in Canada, the United States, Japan, Nepal, and India.

\section{References}

Afflerbach, P., Pearson, P. D., \& Paris, S. (2008). Skills and strategies: Their differences, their relationships, and why it matters. In K. Mokhtari, \& R. Sheorey (Eds.), Reading strategies of first- and second-language learners: See how they read (pp. 11-24). Norwood, MA: ChristopherGordon Publishers.

Akkakoson, S. (2012). Raising strategic awareness of Thai EFL students of science and technology disciplines through metacognitive strategy training. 3L: Language, Linguistics and LiteratureThe Southeast Asian Journal of English Language Studies, 18(4), 35-47.

Alhaqbani, A., \& Riazi, M. (2012). Metacognitive awareness of reading strategy use in Arabic as a second language. Reading in a Foreign Language, 24(2), 231-255.

Allen, S. (2003). An analytic comparison of three models reading strategy instruction. International Review of Applied Linguistics, 41, 319-338.

Alsheikh, N. O. (2011). Three readers, three languages, three texts: The strategic reading of multilingual and multiliterate readers. The Reading Matrix, 11(1), 34-53.

Anderson, N. J. (1991). Individual differences in strategy use in second language reading and testing. The Modern Language Journal, 75(4), 466-472.

Anderson, N. J. (2002). The role of metacognition in second/foreign language teaching and learning. ERIC Digests. Washington, DC: ERIC Clearinghouse on Languages and Linguistics.

Anderson, L. W., Krathwohl, D. R., Airasian, P. W., Cruikshank, K. A., Mayer, R. E., Pintrich, P. R., Raths, J., \& Wittrock, M. C. (2001). A taxonomy for learning, teaching, and assessing: A revision of Bloom's Taxonomy of educational objectives (Complete edition). New York, NY: Longman.

Barnett, M. A. (1988). Reading through context: How reading and perceived strategy use affects L2 comprehension. The Modern Language Journal, 72(2), 150-162.

Block, E L. (1992). See how they read: Comprehension monitoring of L1 and L2 readers. TESOL Quarterly, 26(2), 319-343. 
Brantmeier, C. (2002). Second language reading strategy research at the secondary and university levels: Variations, disparities, and generalizability. The Reading Matrix, 2(3), 1-14.

Burns, A. (2005). Action research: An evolving paradigm? Language Teaching, 38(2), 57-74.

Burns, A. (2010). Doing action research in English language teaching: A guide for practitioners. New York, NY: Routledge.

Carrell, P. L. (1998). Can reading strategies be successfully taught? The Language Teacher. Retrieved from http://jalt-publications.org/old_tlt/files/98/mar/carrell.html

Cambridge IELTS 7 (2012): Examination papers from the University of Cambridge. (6th ed.). Cambridge, UK: Cambridge University Press.

Cambridge IELTS 11 Academic (2016): Authentic examination papers. Cambridge, UK: Cambridge University Press.

Chaury, P. (2015). The effects of strategy instruction on reading comprehension in English as a foreign language. Concordia Working Papers in Applied Linguistics, 6, 1-26.

Cohen, A. D. (2011). Strategies in learning and using a second language. Harlow, UK: Pearson Education.

Cohen, A. D., \& Macaro, E. (Eds.). (2007). Language learner strategies: Thirty years of research and practice. New York, NY: Oxford University Press.

Creswell, J. W. (2011). Designing and conducting mixed methods research. Thousand Oaks, CA: Sage.

Dewey, J. (1933). How we think: A restatement of the relation of reflective thinking to the educative process. New York, NY: D.C. Heath and Company.

Dörnyei, Z. (2005). The psychology of the language learner: Individual differences in second language acquisition. Mahwah, NJ: Erlbaum.

Evans, S. (2008). Reading reaction journals in EAP Courses. ELT Journal, 62(3), 240-270.

Ghavamnia, M., Ketabi, S., \& Tavakoli, M. (2013). L2 reading strategies used by Iranian ELF learners: A think-aloud study. Reading Psychology, 34(4), 355-378.

Grabe, W. (2009). Reading in a second language: Moving from theory to practice. New York, NY: Cambridge University Press.

Grabe, W., \& Stoller, F. L. (2011). Teaching and researching reading (2nd ed.). Harlow, UK: Pearson Education.

Huang, L.-S. (2010a). Seeing eye to eye? The academic writing needs of graduate and undergraduate students' and instructors' perspectives. Language Teaching Research, 14(4), 517-539.

Huang, L.-S. (2010b). Do different modalities of reflection matter? An exploration of adult second-language learners' reported strategy use and oral language production. System: An International Journal of Educational Technology and Applied Linguistics, 38(2), 245-261.

Huang, L.-S. (2012). Use of oral reflection in facilitating graduate EAL students' oral-language production and strategy use: An empirical action research study. International Journal for the Scholarship of Teaching and Learning, 6(2), 1-22.

Huang, L.-S. (2013a). Using a reflection app-iLanguaging - to mediate the development of oral communication skills. Contact TESOL Ontario Magazine, 39(4), 7-13.

Huang, L.-S. (2013b). Cognitive processes involved in performing the IELTS speaking test: Respondents' strategic behaviours in simulated testing and non-testing contexts. IELTS Research Reports Online Series, No. 1. Retrieved from https://www.ielts.org/-/media/researchreports/ielts_online_rr_2013-1.ashx

Hudson, T. (2007). Teaching second language reading. Oxford, UK: Oxford University Press.

Ivankova, N. V., \& Kawamura, Y. (2010). Emerging trends in the utilization of integrated designs in social, behavioral, and health sciences. In A. Tashakkori \& C. Teddlie (Eds.), Sage handbook of mixed methods in social $\mathcal{E}$ behavioral research (2nd ed., pp. 581-611). Thousand Oaks, CA: Sage.

Ivankova, N. V. (2015). Mixed methods applications in action research: From methods to community action. Thousand Oaks, CA: Sage.

Kern, R. G. (1989). Second language reading strategy instruction: Its effects on comprehension and word inferences ability. Modern Language Journal, 73(2), 135-149. 
Küçükoğlu, H. (2013). Improving reading skills through effective reading strategies. ProcediaBehavioral Sciences, 70, 709-714.

Lei, L., \& Liu, D. (2018). The research trends and contributions of System's publications over the past four decades (1973-2017): A bibliometric analysis. System, 30, 1-13. doi.org/10.1016/j. system.2018.10.003

Li, S., \& Munby, H. (1996). Metacognitive strategies in second language academic reading: A qualitative investigation. English for Specific Purposes, 15(3), 199-216.

Maasum, T., \& Maarof, N. (2012). Empowering ESL readers with metacognitive reading strategies. Procedia-Social and Behavioral Science, 69, 1250-1258.

Macaro, E. (2001). Learning strategies in foreign and second language classrooms. New York, NY: Continuum.

Magogwe, J. M. (2013). Metacognitive awareness of reading strategies of University of Botswana English as second language students of different academic reading proficiencies. Reading $\mathcal{E}$ Writing, 4(1), 1-8.

Malcolm, D. (2009). Reading strategy awareness of Arabic-speaking medical students studying in English. System, 37(4), 644-651.

McNiff, J. (2013). Action research principles and practice (3rd ed.). New York, NY: Routledge.

Mills, G. E. (2011). Action research: A guide for the teacher researcher (4th ed.). Boston, MA: Pearson Education.

Mokhtari, K., \& Sheorey, R. (2002). Measuring ESL students' awareness of reading strategies. Journal of Developmental Education, 25, 2-10.

Mokhtari, K., \& Sheorey, R. (Eds.). (2008). Reading Strategies of first- and second-language learners: See how they read. Norwood, MA: Christopher-Gordon.

O'Malley, J. M., \& Chamot, A. U. (1990). Learning strategies in second language acquisition. Cambridge, UK: Cambridge University Press.

Oxford, R. L. (1990). Language learning strategies: What every teacher should know. Boston: Heinle $\&$ Heinle.

Oxford, R., \& Crookall, D. (1989). Research on language learning strategies: Methods, findings, and instructional issues. Modern Language Journal, 73, 404-419.

Phakiti, A. (2006). Theoretical and pedagogical issues in ESL/EFL teaching of strategic reading. University of Sydney Papers in TESOL, 1, 19-50.

Plonsky, L. (2011). The effectiveness of second language strategy instruction: A meta-analysis. Language Learning, 61(4), 993-1038.

Poole, A. (2005). Gender differences in reading strategy use among ESL college students. Journal of College Reading and Learning, 36(1), 7-20.

Ryan, J., \& Carroll, J. (2005). Canaries in the coalmine: International students in Western universities. In J. Carroll \& J. Ryan (Eds.), Teaching international students: Improving learning for all (pp. 3-10). New York, NY: Routledge.

Salataci, R., \& Akyel, A. (2002). Possible effects of strategy instruction on L1 and L2 reading. Reading in a Foreign Language, 14(1), 1-17.

Savin-Baden, M. \& Major, C. H. (2013). Qualitative research: The essential guide to theory and practice. New York, NY: Routledge.

Statistics Canada (2018). Postsecondary enrolments, by student status, country or citizenship and sex. Retrieved from: https://www150.statcan.gc.ca/t1/tbl1/en/tv.action?pid=3710008601

Stringer, E. T. (2014). Action research (4th ed.). Thousand Oaks, CA: Sage.

Yüksel, İ., \& Yüksel, İ. (2012). Metacognitive awareness of academic reading strategies. ProcediaSocial and Behavioral Sciences, 31, 894-898.

Zhou, J., \& Huang, L.-S. (2018). An exploration of strategies used by Chinese graduate students in electrical engineering and education: Integrating questionnaire, task performance, and post-task recall data. Asian-Pacific Journal of Second and Foreign Language Education, 3(15), $1-22$. 